\title{
Author Correction: Enabling low voltage losses and high photocurrent in fullerene-free organic photovoltaics
}

Jun Yuan 1,2,3, Tianyi Huang ${ }^{1}$, Pei Cheng (1) 1, Yingping Zou², Huotian Zhang (1) 4, Jonathan Lee Yang ${ }^{5}$, Sheng-Yung Chang ${ }^{1}$, Zhenzhen Zhang ${ }^{2}$, Wenchao Huang ${ }^{1}$, Rui Wang ${ }^{1}$, Dong Meng ${ }^{1,3}$, Feng Gao ${ }^{4} \&$ Yang Yang ${ }^{1,3}$

Correction to: Nature Communications https://doi.org/10.1038/s41467-019-08386-9, published online 04 February 2019

The original PDF version of this Article contained an error in the Additional information section, which incorrectly included the statement 'This is a U.S. Government work and not under copyright protection in the US; foreign copyright protection may apply 2019'. This has been removed from the PDF version of the Article. The HTML version was correct from the time of publication.

Published online: 03 April 2019

(i) Open Access This article is licensed under a Creative Commons Attribution 4.0 International License, which permits use, sharing, adaptation, distribution and reproduction in any medium or format, as long as you give appropriate credit to the original author(s) and the source, provide a link to the Creative Commons license, and indicate if changes were made. The images or other third party material in this article are included in the article's Creative Commons license, unless indicated otherwise in a credit line to the material. If material is not included in the article's Creative Commons license and your intended use is not permitted by statutory regulation or exceeds the permitted use, you will need to obtain permission directly from the copyright holder. To view a copy of this license, visit http://creativecommons.org/licenses/by/4.0/.

(C) The Author(s) 2019

\footnotetext{
${ }^{1}$ Department of Materials Science and Engineering, University of California, Los Angeles, 90095 Los Angeles, CA, USA. ${ }^{2}$ College of Chemistry and Chemical Engineering, Central South University, 410083 Changsha, China. ${ }^{3}$ California NanoSystems Institute, University of California, Los Angeles, Los Angeles, CA 90095, USA. ${ }^{4}$ Department of Physics, Chemistry and Biology (IFM), Linköping University, 58183 Linköping, Sweden. ${ }^{5}$ College of Chemistry, University of California, Berkeley, CA 94720, USA. These authors contributed equally: Jun Yuan, Tianyi Huang, Pei Cheng. Correspondence and requests for materials should be addressed to Y.Z. (email: yingpingzou@csu.edu.cn) or to F.G. (email: feng.gao@liu.se) or to Y.Y. (email: yangy@ucla.edu)
} 